Ciência e Natura, v. 37 Part 2 jun. 2015, p. 195-204

\title{
Simulation and Comparison of Control Methods of Doubly Fed Induction Generator in Energy Conversion System
}

\author{
Omid Rahmani ${ }^{1}$, Parviz Amiri 2, Zahra Mokhtari ${ }^{3}$, Zhale Amirjamshidi 4
}

${ }^{1}$ Research Laboratory of Industrial circuits \& systems, Shahid Rajae teacher training University, Iran

${ }^{2}$ Research Laboratory of Industrial circuits \& systems, Shahid Rajae teacher training University, Iran

${ }^{3}$ Research Laboratory of Industrial circuits \& systems, Shahid Rajae teacher training University, Iran

${ }^{4}$ Research Laboratory of Industrial circuits \& systems, Shahid Rajae teacher training University, Iran

\begin{abstract}
One of the most applicable methods for utilization of wind energy is the use of doubly fed induction generator (DFIG). This paper presents two various strategies for control of DFIG in wind energy conversion system. Two most common and best control methods are implemented vector control and direct torque control. The studied control methods and their performance have been compared and analyzed based on the results of stimulation. The results indicate the fact that although direct torque control method is a bit slow at the start time; due to less usage of machine parameters, less complexity of control algorithm and improvement of transient response speed of the system, this method presents better performance compared to vector control method.
\end{abstract}

Keywords: Vector control, direct torque control, doubly fed induction generator, back to back convertor, wind energy. 


\section{Introduction}

W

ind energy capacity all over the world has increasing grown in recent years. In 2008, the global capacity with $29 \%$ increase passed 93.9 GB and reached above 121 GB. In 2009, despite financial crisis, the total capacity of wind energy in the world increased 31\% and reached 157.9 GW (WWEA Report, 2011). Nowadays, the use of DFIG is ideal due to flexibility, strength and being multi-capacity; thus, it becomes one of the most applicable methods for utilization of wind energy. In spite of the presence of networks connected to wind energy conversion system (WECS) working according to DFIG technology, it still confronts with various challenges such as stability of the system, the quality of power (Nunes et al, 2004), (Tremblay et al, 2006), low voltage, currency errors, phase imbalance (Xiang et al, 2006) and Maximum Power Point Tracker (MPPT) (Shen et al, 2009). Anyway, the point that should be considered is to control the device by itself. Various methods have been presented for control in the papers including simple controllers with somehow high error and slippage to complex and flexible controllers and vector control (VC) (Blaschke, 1974), (Pena et al, 1996) and Direct Torque Control (DTC) (Tamalouzt et al, 2014), (Chandrakala et al, 2012). This paper compares two kinds of DFIG control methods which are VC and DTC.

In this paper, a basic and essential study has been conducted through VC and DTC methods that are among DFIG control methods with good performance. In the second part that is DFIG in WECS, after explaining the configuration of Scherbius drive, DFIG pattern will be introduced. Then, in third part, VC method will be presented including an introduction on $\mathrm{VC}$, VC schematic, the results of stimulation with VC. In the fourth part, DTC will be explained in different subsections including an introduction on DTC, DTC schematic and the results of stimulation with DTC. Then, the performance of control strategies and finally conclusion will be presented.

\section{DFIG in WECS}

\subsection{Scherbius configuration}

Some of the experimental results concerning the duration of DFIG usage in varied speed wind turbine has been presented in (Pena et al, 1996).

In a system with back to back convertor controlled by VC, the proposed configuration of Scherbius is able to regulate directly active and reactive power.

Scherbius standard configuration which is a system connected to WECS based on DFIG is presented in Figure 1. As can be seen in Figure 1, wind turbine transfers mechanical power through gearbox. This gearbox is calibrated based on nominal speed of turbine, the number of bipolar generators and the frequency of system.



Figure 1: System connected to DFIG. 
Wind speed, aerodynamic turbine and quiescent pointchange the produced electrical power.

Slip power depending on wind speed, aerodynamic turbine and quiescent point flows from/to rotor circuit through back to back convertor consisting of a rotor side convertor (RSC) for machine control and controller of grid side convertor (GSC) for regulation of DC and control of power coefficient in point of common coupling (PCC).

\subsection{DFIG pattern}

DFIG is two groups of three-phase winding including its own windings and opposite inductance. The varied mathematical model with machine time is obtained by the change of opposite inductance at the time of rotation of machine and the change of angle between the rotor circuits and stator with time.

Dependency on the angle in DFIG pattern and its related complexities is removed by the following items.

1) Change of values from three abc phase to biaxial values of $\alpha \beta$ (Clark transfer)

2) Change of $\alpha \beta$ values to orthogonal and direct $\mathrm{dq}$ components that refer to rotating Sancron reference frame (SRF) of dq (Park transfer).

According to (Krause et al, 2002), DFIG model is obtained in SRF dq with (1-a) to (1-g).

$$
\begin{aligned}
& \mathrm{v}_{\mathrm{qs}}=\mathrm{R}_{\mathrm{s}} \mathrm{i}_{\mathrm{qs}}+\mathrm{s} \lambda_{\mathrm{qs}}+\omega_{\mathrm{e}} \lambda_{\mathrm{ds}} \\
& \mathrm{v}_{\mathrm{ds}}=\mathrm{R}_{\mathrm{s}} \mathrm{i}_{\mathrm{ds}}+\mathrm{s} \lambda_{\mathrm{ds}}-\omega_{\mathrm{e}} \lambda_{\mathrm{qs}} \\
& \mathrm{v}_{\mathrm{qr}}^{\prime}=\mathrm{R}_{\mathrm{r}}^{\prime} \mathrm{i}_{\mathrm{qr}}^{\prime}+\mathrm{s} \lambda_{\mathrm{qr}}^{\prime}+\left(\omega_{\mathrm{e}}-\omega_{\mathrm{r}}\right) \lambda_{\mathrm{dr}}^{\prime} \\
& \mathrm{v}_{\mathrm{dr}}^{\prime}=\mathrm{R}_{\mathrm{r}}^{\prime} \mathrm{i}_{\mathrm{dr}}^{\prime}+\mathrm{s} \lambda_{\mathrm{dr}}^{\prime}-\left(\omega_{\mathrm{e}}-\omega_{\mathrm{r}}\right) \lambda_{\mathrm{qr}}^{\prime} \\
& \lambda_{\mathrm{qs}}=\mathrm{L}_{\mathrm{s}} \mathrm{i}_{\mathrm{is}}+\mathrm{L}_{\mathrm{M}} \mathrm{i}_{\mathrm{qr}}^{\prime} ; \lambda_{\mathrm{ds}}=\mathrm{L}_{\mathrm{s}} \mathrm{i}_{\mathrm{ds}}+\mathrm{L}_{\mathrm{M}} \mathrm{i}_{\mathrm{dr}}^{\prime} \\
& \lambda_{\mathrm{qr}}^{\prime}=\mathrm{L}_{\mathrm{r}}^{\prime} \mathrm{i}_{\mathrm{qr}}+\mathrm{L}_{\mathrm{M}} \mathrm{i}_{\mathrm{qs}} ; \lambda_{\mathrm{dr}}^{\prime}=\mathrm{L}_{\mathrm{r}}^{\prime} \mathrm{i}_{\mathrm{dr}}^{\prime}+\mathrm{L}_{\mathrm{M}} \mathrm{i}_{\mathrm{ds}} \\
& \mathrm{T}_{\mathrm{e}}=3 /{ }_{2} \mathrm{P}_{\mathrm{p}}\left(\lambda_{\mathrm{ds}} \mathrm{i}_{\mathrm{qs}}-\lambda_{\mathrm{qs}} \mathrm{i}_{\mathrm{ds}}\right)
\end{aligned}
$$

where,

$$
\mathrm{L}_{\mathrm{s}}=\mathrm{L}_{\mathrm{ls}}+\mathrm{L}_{\mathrm{M}} ; \quad \mathrm{L}_{\mathrm{r}}^{\prime}=\mathrm{L}_{\mathrm{lr}}^{\prime}+\mathrm{L}_{\mathrm{M}} ; \quad \mathrm{L}_{\mathrm{M}}=3 \mathrm{~L}_{\mathrm{ms}} / 2
$$

where, $\mathrm{v}_{\mathrm{s}}$ and $\mathrm{v}_{\mathrm{r}}^{\prime}$ are stator and rotator voltages, $i_{s}$ and $i_{r}^{\prime}$ are stator and rotator currents, $\lambda_{\mathrm{s}}$ and $\lambda_{\mathrm{r}}^{\prime}$ are stator and rotator fluxes, $\mathrm{R}_{\mathrm{s}}$ and $\mathrm{R}_{\mathrm{r}}^{\prime}$ are stator and rotator strength, $\omega_{\mathrm{e}}$ and $\omega_{\mathrm{r}}$ are electric and mechanic speed of rotor, $\mathrm{L}_{\mathrm{s}}, \mathrm{L}_{\mathrm{r}}^{\prime}$ and $\mathrm{L}_{\mathrm{M}}$ are stator and rotator and opposite inductances, $T_{e}$ is electromagnetic torque, $P_{p}$ is the bipolar machine, $\mathrm{L}_{1 s}$ and $\mathrm{L}_{1 \mathrm{r}}^{\prime}$ are stator and rotor infiltrate inductance, $\mathrm{L}_{\mathrm{ms}}$ is magnetic inductance of stator and $\mathrm{s}$ is the derivation operator.

\section{DFIG vector control}

\subsection{Introduction on VC}

In the system connected to DFIG, regardless of the effect of stator strength and assuming the voltages, the stator flux should be constant and applied by the voltage. The stator flux vector is obtained in static coordination $\alpha \beta$ from (2) (Tremblay et al, 2011).

$\lambda_{\alpha \beta s}=\int\left(v_{\alpha \beta s}-R_{s} i_{\alpha \beta s}\right) d t$

Concerning the above equation, it is possible to simplify equation (1-a) to (1-d) by coordination of stator flux vector $\lambda_{s}$ in (3) with direct vector of $\mathrm{dq}$ rotating reference frame; while,

$\lambda_{s}=\left|\lambda_{\alpha \beta}\right| \angle\left(\lambda_{\alpha \beta}\right)$

where,

$$
\angle\left(\lambda_{\alpha \beta}\right)=\tan ^{-1}\left(\lambda_{\alpha} / \lambda_{\beta}\right) ;\left|\lambda_{\alpha \beta}\right|=\sqrt{\lambda_{\alpha}^{2}+\lambda_{\beta}^{2}}
$$

The simple model for DFIG can be obtained from (4-a) to (4-d) (Krause et al, 2002).

$$
\begin{aligned}
\mathrm{v}_{\mathrm{qs}} & =\omega_{\mathrm{e}} \lambda_{\mathrm{ds}}=\mathrm{v}_{\mathrm{s}} \\
\mathrm{v}_{\mathrm{ds}} & =0 \\
\mathrm{v}_{\mathrm{qr}}^{\prime} & =\mathrm{R}_{\mathrm{r}}^{\prime} \mathrm{i}_{\mathrm{qr}}^{\prime}+\sigma \mathrm{L}_{\mathrm{r}}^{\prime} \mathrm{si}_{\mathrm{qr}}^{\prime}+\omega_{\text {slip }}\left(\frac{\mathrm{L}_{\mathrm{M}}^{2}}{\mathrm{~L}_{\mathrm{s}}} \mathrm{I}_{\mathrm{ms}}+\sigma \mathrm{L}_{\mathrm{r}}^{\prime} \mathrm{i}_{\mathrm{dr}}^{\prime}\right) \\
\mathrm{v}_{\mathrm{dr}}^{\prime} & =\mathrm{R}_{\mathrm{r}}^{\prime} \mathrm{i}_{\mathrm{dr}}^{\prime}+\sigma \mathrm{L}_{\mathrm{r}}^{\prime} \mathrm{si}_{\mathrm{dr}}^{\prime}-\omega_{\text {slip }} \sigma \mathrm{L}_{\mathrm{r}}^{\prime} \mathrm{i}_{\mathrm{qr}}^{\prime}
\end{aligned}
$$

where,

$$
\begin{gathered}
\lambda_{\mathrm{ds}}=\lambda_{\mathrm{s}} \cong \mathrm{L}_{\mathrm{M}} \mathrm{I}_{\mathrm{ms}} ; \lambda_{\mathrm{qr}}^{\prime}=\sigma \mathrm{L}_{\mathrm{r}}^{\prime} \mathrm{i}_{\mathrm{qr}}^{\prime} \\
\lambda_{\mathrm{qr}}^{\prime}=\mathrm{L}_{\mathrm{M}}^{2} \mathrm{I}_{\mathrm{ms}} / \mathrm{L}_{\mathrm{s}}+\sigma \mathrm{L}_{\mathrm{r}}^{\prime} \mathrm{i}_{\mathrm{dr}}^{\prime} ; \mathrm{I}_{\mathrm{ms}}=\lambda_{\mathrm{ds}} / \mathrm{L}_{\mathrm{M}} \\
\sigma=1-\mathrm{L}_{\mathrm{M}}^{2} /\left(\mathrm{L}_{\mathrm{s}} \mathrm{L}_{\mathrm{r}}^{\prime}\right)
\end{gathered}
$$

In which, $\sigma$ is the leakage coefficient and $\omega_{\text {slip }}$ is angular rotating velocity.

By solving (4-c) and (4-d) expressions; an expression will be obtained for $\mathrm{i}_{\mathrm{qr}}^{\prime}(5-\mathrm{a})$ and $\mathrm{i}_{\mathrm{dr}}^{\prime}$ (5-b) from rotor voltage equations $v_{\mathrm{qr}}^{\prime}, \mathrm{v}_{\mathrm{dr}}^{\prime}$ and EMF $v_{\mathrm{q}}$ component due to $\omega_{\text {slip }}$. 
$\mathrm{i}_{\mathrm{qr}}^{\prime}=-\frac{\mathrm{R}_{\mathrm{r}}^{\prime}}{\sigma \mathrm{L}_{\mathrm{r}}^{\prime}} \mathrm{i}_{\mathrm{qr}}^{\prime}+\frac{1}{\sigma \mathrm{L}_{\mathrm{r}}^{\prime}} \mathrm{v}_{\mathrm{qr}}^{\prime}-\omega_{\text {slip }} \mathrm{i}_{\mathrm{dr}}^{\prime}+\mathrm{v}_{\mathrm{q}}^{\prime}$

$\mathrm{i}_{\mathrm{dr}}^{\prime}=-\frac{\mathrm{R}_{\mathrm{r}}^{\prime}}{\sigma \mathrm{L}_{\mathrm{r}}^{\prime}} \mathrm{i}_{\mathrm{dr}}^{\prime}+\frac{1}{\sigma \mathrm{L}_{\mathrm{r}}^{\prime}} \mathrm{v}_{\mathrm{dr}}^{\prime}-\omega_{\text {slip }} \mathrm{i}_{\mathrm{qr}}^{\prime}$

where,

$$
\mathrm{v}_{\mathrm{q}}^{\prime}=\frac{\omega_{\text {slip }} \mathrm{L}_{\mathrm{M}}^{2} \mathrm{I}_{\mathrm{ms}}}{\sigma \mathrm{L}_{\mathrm{r}}^{\prime} \mathrm{L}_{\mathrm{s}}}
$$

\subsection{VC Schematic for DFIG}

VC controller is shown in Figure 2 (Tremblay et al, 2011). As can be seen, rotor flow ( $i_{a_{-}}$) transfers to reference frame dq $\left(i_{d q r}^{\prime}\right)$ after measurement. Then, it is reduced from reference flows $\left(i_{\mathrm{dqr}}^{*}\right)$ and error signals will be calculated. This signal has the duty of installing two PI controllers.

Two expressions $\omega_{\text {slip }}\left(\mathrm{L}_{\mathrm{M}}^{2} \mathrm{I}_{\mathrm{ms}} / \mathrm{L}_{\mathrm{s}}+\sigma \mathrm{L}_{\mathrm{r}}^{\prime} \mathrm{i}_{\mathrm{dr}}^{\prime}\right)$ and $-\omega_{\text {slip }} \sigma \mathrm{L}_{\mathrm{r}}^{\prime} \mathrm{i}_{\text {qr }}^{\prime}$ are added to the output of PI controllers for compensation to combine $1 / 4$ of voltage sources $\left(\mathrm{v}_{\mathrm{qr}}^{*}\right)$ and direct $\left(\mathrm{v}_{\mathrm{dr}}^{*}\right)$, then $\mathrm{v}_{\mathrm{qr}}^{*}$ and $\mathrm{v}_{\mathrm{dr}}^{*}$ are transformed to three-phase $\mathrm{V}_{\mathrm{abc}}$ voltages to be applied to rotor circuit by RSC.

Two angular situations are needed for necessary transformation of reference frame: 1Mechanical angle of rotor $\theta_{\mathrm{m}}$ and 2- The angular situation of stator flux $\theta_{\mathrm{e}}=\angle \lambda_{\alpha \beta}$ that can be obtained from (2) and (3).

Reference flows $i_{\mathrm{qr}}^{*}$ and $\mathrm{i}_{\mathrm{dr}}^{*}$ are respectively related to electric torque and power coefficient in stator part. $\mathrm{i}_{\mathrm{dr}}^{*}$ (6) can be obtained concerning unit power coefficient (i.e. $\mathrm{i}_{\mathrm{ds}}=0$ ) and $\mathrm{i}_{\mathrm{qr}}^{*}(7) \mathrm{can}$ be obtained by solving (1-e) equation for idq and then placing in (1-g) equation.

$$
\begin{aligned}
& \mathrm{i}_{\mathrm{dr}}^{\prime *}=\mathrm{v}_{\mathrm{qs}} /\left(\omega_{\mathrm{e}} \mathrm{L}_{\mathrm{M}}\right) \\
& \mathrm{i}_{\mathrm{qr}}^{\prime *}=-2 \mathrm{~T}_{\mathrm{e}} \mathrm{L}_{\mathrm{s}} /\left(3 \mathrm{P}_{\mathrm{p}} \mathrm{L}_{\mathrm{M}}^{2} \mathrm{i}_{\mathrm{dr}}^{\prime *}\right)
\end{aligned}
$$

\subsection{The results of stimulation with VC}

Stimulation has been done in Simulink/Matlab. In Figure 3, the results of stimulation of VC controller have been presented. First, stimulation of wind turbine of induction generator in Matlab is separate from the system. The values of parameters of DFIG in this paper have been presented in Table 1 and the stimulation has been done in dq reference.

Considerable performance of controller can be observed in stimulation.

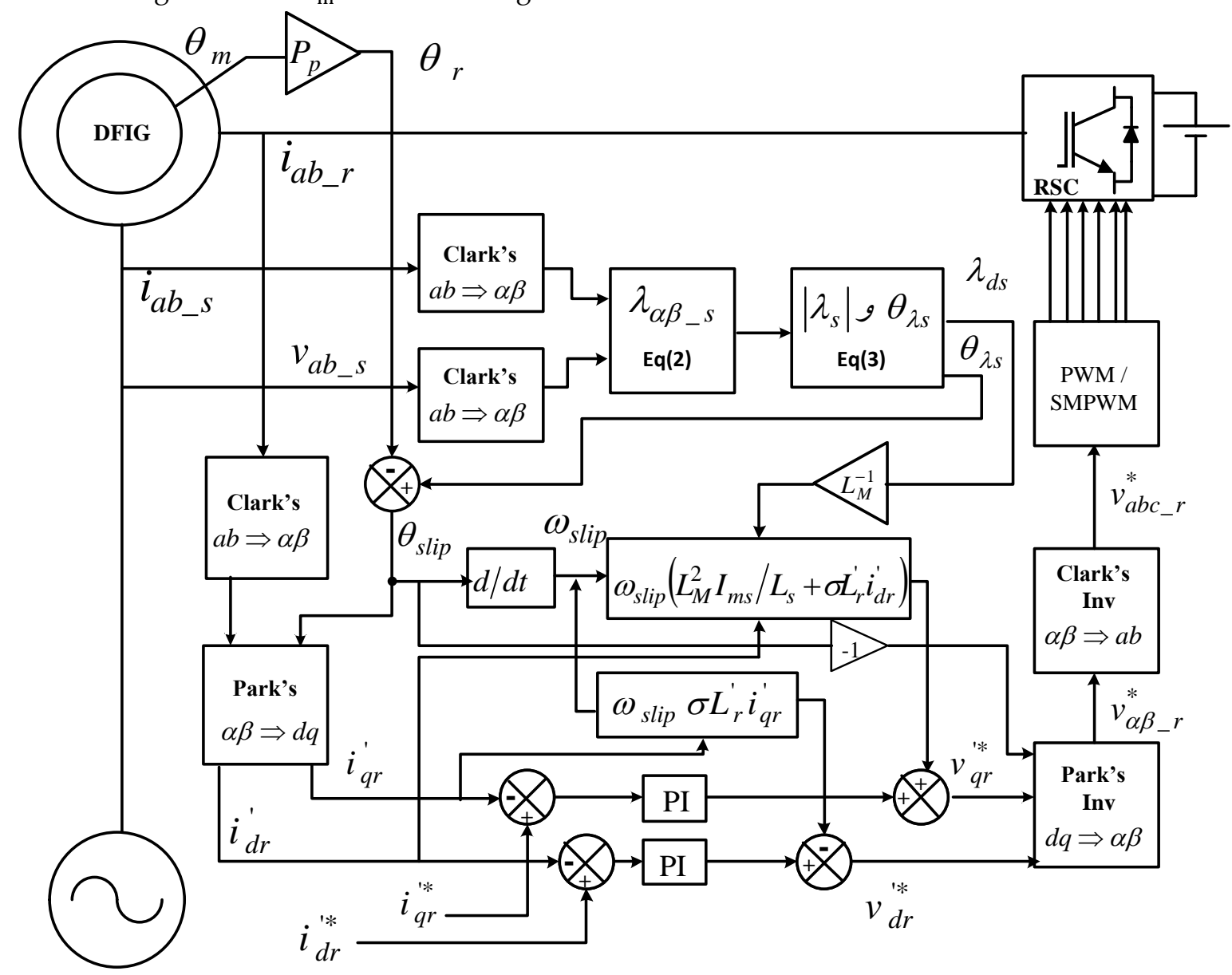

Figure 2: WESC vector control schematic based on DFIG. 



Figure 3: (a) Desired flow and system flow, (b) stator flows, (c) active power, (d) reactive power, (e) torque.

\section{DTC torque control}

\subsection{Introduction on DTC}

Direct control techniques have considerable capability in applying certain voltage to system by digital electronic controller converters in a small portion of time.
Ignoring the strengths of device, Figure 4 shows the simple stator and rotor DFIG circuits that are respectively connected to RSC system.

$\lambda_{\mathrm{S}}$ stator flux is directly produced by the system voltage and the size and angle of rotor flux could be completely controlled by applying appropriate voltage to rotor circuit using RSC.

DFIG electric torque $\left(\mathrm{T}_{\mathrm{e}}\right.$ ) and flux (e.g. active and reactive power) are obtained based on controlling the angle between stator and rotor flux and rotor flux vector $\gamma$ and rotor magnetic flux $\left|\lambda_{\mathrm{r}}\right|$. 


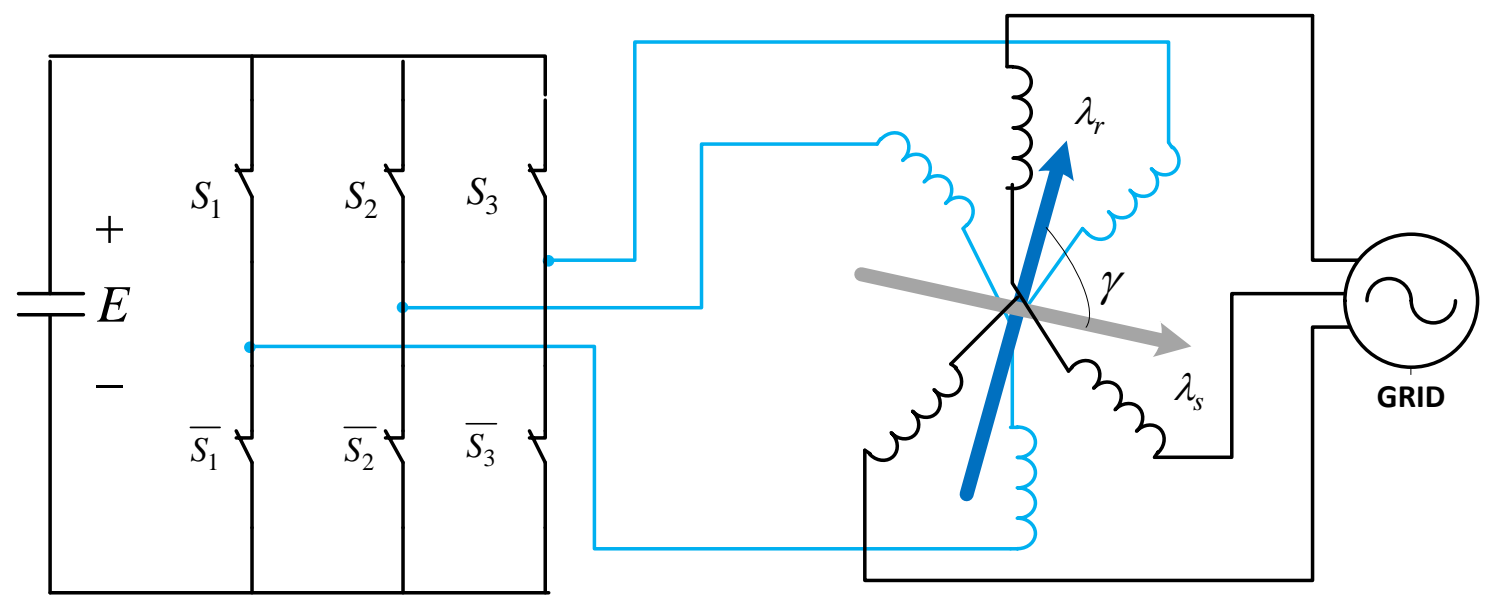

Figure 4: Simple DFIG stator and rotor circuit.

Table 1: The values of stimulated DFIG parameters.

\begin{tabular}{|l|c|}
\hline $\begin{array}{l}\text { Induction generator power } \\
\text { rating }\end{array}$ & $3 \mathrm{KW}$ \\
\hline frequency & $0-50 \mathrm{~Hz}$ \\
\hline Stator resistance & $\mathrm{R}_{\mathrm{s}}=12.5 \Omega$ \\
\hline Stator leakage inductance & $\mathrm{L}_{\mathrm{s}}=23.3 \mathrm{mH}$ \\
\hline Rotor resistance & $\mathrm{R}_{\mathrm{r}}=3.9 \Omega$ \\
\hline Rotor leakage inductance & $\mathrm{L}_{\mathrm{r}}=23.3 \mathrm{mH}$ \\
\hline Magnetizing inductance & $\mathrm{L}_{\mathrm{m}}=477 \mathrm{mH}$ \\
\hline Bipolar Machine & $\mathrm{P}_{\mathrm{p}}=2$ \\
\hline Line Voltage & $\mathrm{DC}=120 \mathrm{~V}$ \\
\hline Maximum Power & $\mathrm{P}_{\mathrm{MAX}}=0.75 \mathrm{~kW}$ \\
\hline
\end{tabular}

Some of the main specifications of DTC strategy are as follow:

1) DFIG electric torque is proportionate to multiplication of $\lambda_{\mathrm{S}}$ and $\lambda_{\mathrm{r}}$. In (8), the constant coefficient $\mathrm{k}$ depends on the parameters of the device (Tremblay et al, 2011).

$\left|\mathrm{T}_{\mathrm{e}}\right|=\mathrm{K}\left|\lambda_{\mathrm{s}}\right|\left|\lambda_{\mathrm{r}}\right| \sin (\gamma)$

2) Eight allowed switch combination $\left(\mathrm{S}_{1}, \mathrm{~S}_{2}, \mathrm{~S}_{3} / \overline{\mathrm{S}_{1}}, \overline{\mathrm{S}_{2}}, \overline{\mathrm{S}_{3}}\right)$ produce six active voltage vectors and two reactive vector (zero) in RSC (as shown in 9). The variation of rotor flux in the voltage vector space is shown in Figure 5 (Tremblay et al, 2011). A 60-degree electric part $(n=1, \ldots ., 6)$ is associated to each active vector.

$v_{n}=3 E\left(s_{1}+s_{2} e^{2 \pi j / 3}+s_{3} e^{4 \pi j / 3}\right) / 2 ; n=0, . .7(9)$

Ignoring rotor strength, the variation of rotor flux $\Delta \lambda_{\mathrm{S}}$ in nth space vector $\mathrm{v}_{\mathrm{n}}$ applied in small time interval of $\Delta \mathrm{t}$ is obtained from (10).

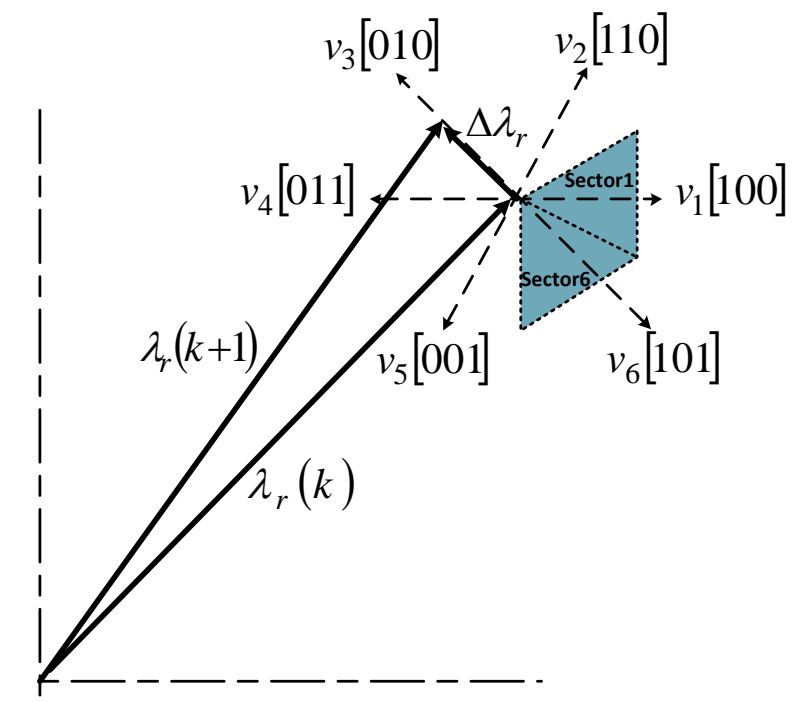

Figure 5: Application of rotor flux $\Delta \lambda_{\mathrm{r}}$ variation as voltage vector in $v_{3}$ space to rotor circuit through RSC.

In discontinuous state, the next status of rotor flux is estimated from (11).

$\Delta \lambda_{\mathrm{r}}=\Delta \mathrm{t} . \mathrm{v}_{\mathrm{n}}$

$\lambda_{\mathrm{r}}(\mathrm{k}+1)=\lambda_{\mathrm{r}}(\mathrm{k})+\Delta \lambda_{\mathrm{r}}$

Figure 5 shows the explained issues.

Depending on the situation of rotor flux and magnetic variations in Teand $\lambda_{\mathrm{r}}$, and optimized voltage vector will be obtained to be applied on the rotor terminal. Thus, DTC is implemented using Table 2 and (12) and (13) (Tremblay et al, 2011).

Table 2 has three inputs and one output. The inputs includes variation in rotor flux $\left(\lambda_{\mathrm{r}+}\right.$ or $\left.\lambda_{\mathrm{r}-}\right)$, torque variations $\left(\mathrm{T}_{\mathrm{e}+}\right.$ or $\mathrm{T}_{\mathrm{e}-}$ or $\left.\mathrm{T}_{\mathrm{e}=}\right)$ and the flow part where the rotor flux flows from. The output is improvement of special vector that is applied on RSC. 
Table 2: The selection of DTC optimum vector.

\begin{tabular}{|l|c|l|l|l|l|l|l|}
\hline Flux & Torque & \multicolumn{2}{|l|}{ Sector } \\
\cline { 2 - 8 } Ref & Ref & 1 & 2 & 3 & 4 & 5 & 6 \\
\hline \multirow{4}{*}{$\lambda_{\mathrm{r}+}$} & $\mathrm{T}_{\mathrm{e}+}$ & $\mathrm{v}_{2}$ & $\mathrm{v}_{3}$ & $\mathrm{v}_{4}$ & $\mathrm{v}_{5}$ & $\mathrm{v}_{6}$ & $\mathrm{v}_{1}$ \\
\cline { 2 - 8 } & $\mathrm{T}_{\mathrm{e}=}$ & $\mathrm{v}_{0}$ & $\mathrm{v}_{7}$ & $\mathrm{v}_{0}$ & $\mathrm{v}_{7}$ & $\mathrm{v}_{0}$ & $\mathrm{v}_{7}$ \\
\cline { 2 - 8 } & $\mathrm{T}_{\mathrm{e}-}$ & $\mathrm{v}_{6}$ & $\mathrm{v}_{1}$ & $\mathrm{v}_{2}$ & $\mathrm{v}_{3}$ & $\mathrm{v}_{4}$ & $\mathrm{v}_{5}$ \\
\hline \multirow{4}{*}{$\lambda_{\mathrm{r}-}$} & $\mathrm{T}_{\mathrm{e}+}$ & $\mathrm{v}_{3}$ & $\mathrm{v}_{4}$ & $\mathrm{v}_{5}$ & $\mathrm{v}_{6}$ & $\mathrm{v}_{1}$ & $\mathrm{v}_{2}$ \\
\cline { 2 - 8 } & $\mathrm{T}_{\mathrm{e}=}$ & $\mathrm{v}_{7}$ & $\mathrm{v}_{0}$ & $\mathrm{v}_{5}$ & $\mathrm{v}_{0}$ & $\mathrm{v}_{7}$ & $\mathrm{v}_{0}$ \\
\cline { 2 - 9 } & $\mathrm{T}_{\mathrm{e}-}$ & $\mathrm{v}_{5}$ & $\mathrm{v}_{6}$ & $\mathrm{v}_{1}$ & $\mathrm{v}_{2}$ & $\mathrm{v}_{3}$ & $\mathrm{v}_{4}$ \\
\hline
\end{tabular}

The required variations of rotor and torque are obtained from (12) and (13).

$\lambda_{\mathrm{r}+} \rightarrow\left|\lambda_{\mathrm{r}}^{*}\right| \geq\left|\lambda_{\mathrm{r}}\right|+\Delta \lambda_{\mathrm{r}}$

$\lambda_{\mathrm{r}-} \rightarrow\left|\lambda_{\mathrm{r}}^{*}\right| \leq\left|\lambda_{\mathrm{r}}\right|-\Delta \lambda_{\mathrm{r}}$

$\mathrm{T}_{\mathrm{e}+} \rightarrow \mathrm{T}_{\mathrm{e}}^{*} \geq\left(\mathrm{T}_{\mathrm{e}}+\Delta \mathrm{T}_{\mathrm{e}}\right)$

$\mathrm{T}_{\mathrm{e}-} \rightarrow \mathrm{T}_{\mathrm{e}}^{*} \leq\left(\mathrm{T}_{\mathrm{e}}-\Delta \mathrm{T}_{\mathrm{e}}\right)$

$\mathrm{T}_{\mathrm{e}} \rightarrow\left(\mathrm{T}_{\mathrm{e}}+\Delta \mathrm{T}_{\mathrm{e}}\right) \geq \mathrm{T}_{\mathrm{e}}^{*} \geq\left(\mathrm{T}_{\mathrm{e}}-\Delta \mathrm{T}_{\mathrm{e}}\right)$

Such that $\lambda_{\mathrm{r}+}$ is used when positive variation is required in the rotor flux. For example, the size of reference flux $\left|\lambda_{\mathrm{r}}^{*}\right|$ is bigger than or equal to sum of real value of flux $\left|\lambda_{r}\right|$ and the predetermined threshold of $\Delta \lambda_{\mathrm{r}}$ flux.
Similar argumentation is used for the remaining expressions. It should be mentioned that $\Delta \mathrm{T}_{\mathrm{e}}$ is the related torque threshold.

Precise estimation of moment electrical torque and rotor flux leads to successful implementation of DTC.

The size of rotor flux $\left|\lambda_{\mathrm{r}}\right|$ and the orientation angle are obtained from (14). In this equation, $\lambda_{\mathrm{qr}}^{\prime}$ and $\lambda_{\mathrm{dr}}^{\prime}$ are obtained from (1-f). Moreover, electrical torque is obtained from (15).

$\left|\lambda_{\mathrm{r}}\right|=\sqrt{\lambda_{\mathrm{qr}}^{\prime 2}+\lambda_{\mathrm{dr}}^{\prime 2}} ; \quad \angle\left(\lambda_{\mathrm{r}}\right)=\tan ^{-1}\left(\lambda_{\mathrm{qr}}^{\prime} / \lambda_{\mathrm{dr}}^{\prime}\right)$

$\widehat{\mathrm{T}_{\mathrm{e}}}=3 \mathrm{~L}_{\mathrm{M}}\left(\mathrm{i}_{\mathrm{qs}} \mathrm{i}_{\mathrm{dr}}^{\prime}-\mathrm{i}_{\mathrm{ds}} \mathrm{i}_{\mathrm{qr}}^{\prime}\right) / 2$

\subsection{DTC schematic for WESC based on DFIG}

Figure 6 (Tremblay et al, 2011) shows complete strategy of DTC. The output of Table 2 directly specifies on/off states of RSC switches and just one transfer reference is required for stator flow for transforming abc constant components to dq rotating components.

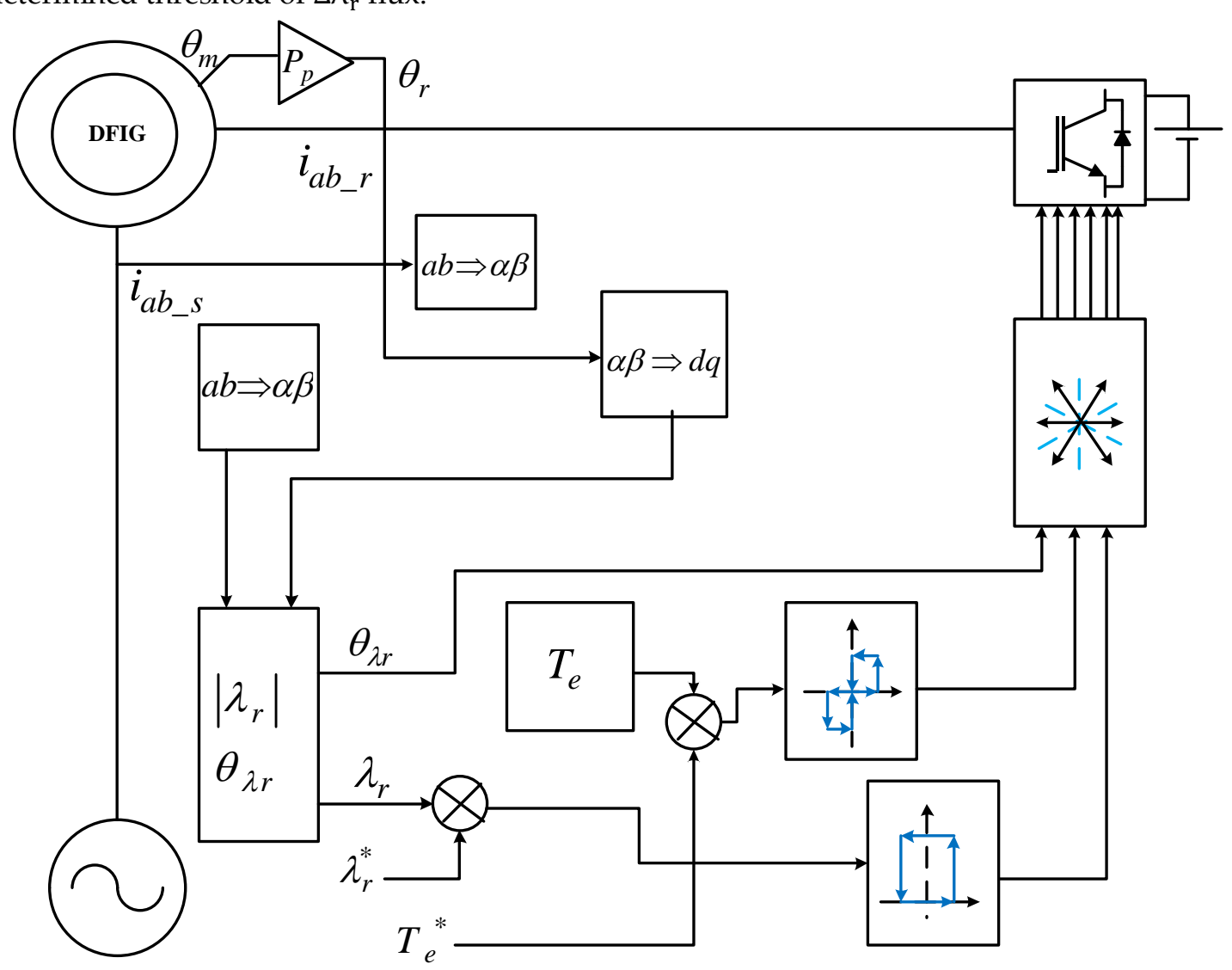

Figure 6: DTC WESC Schematic based on DFIG. 
In this case, rotating reference frame is balanced with rotor electrical angle $\theta_{\mathrm{r}}$. (12) and (13) are equal to a hysteresis controller pair.

\subsection{Stimulation of system with DTC}

Figure 7 shows the results of stimulation for DTC strategy. The values of stimulated DFIG have been presented in Table 1 and the stimulation has been done in dq reference.
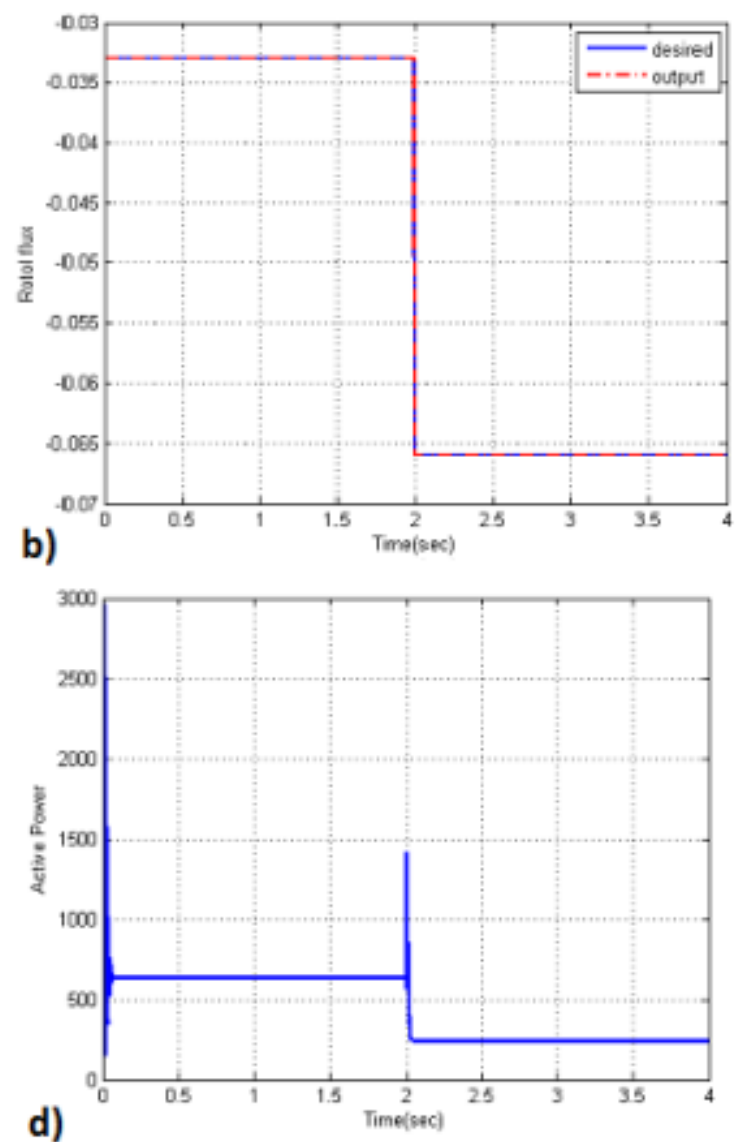

$$
\text { a) }
$$
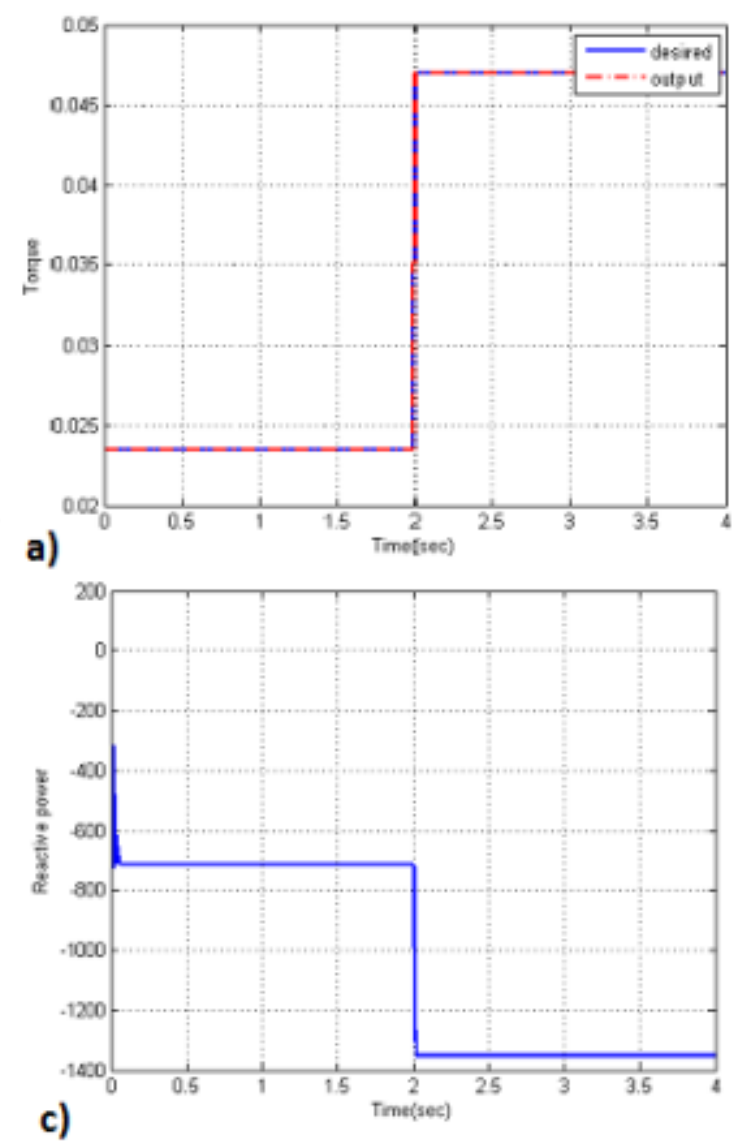

\section{The comparison of the performance of control strategies}

After introducing the main and stimulated specification of VC and DTC controllers, the advantages and disadvantages of these methods at the time of DFIG usage will be expressed.

In Table 3 (Tremblay et al, 2011), the necessary parameters and variables of the device are used for implementation of control strategy.

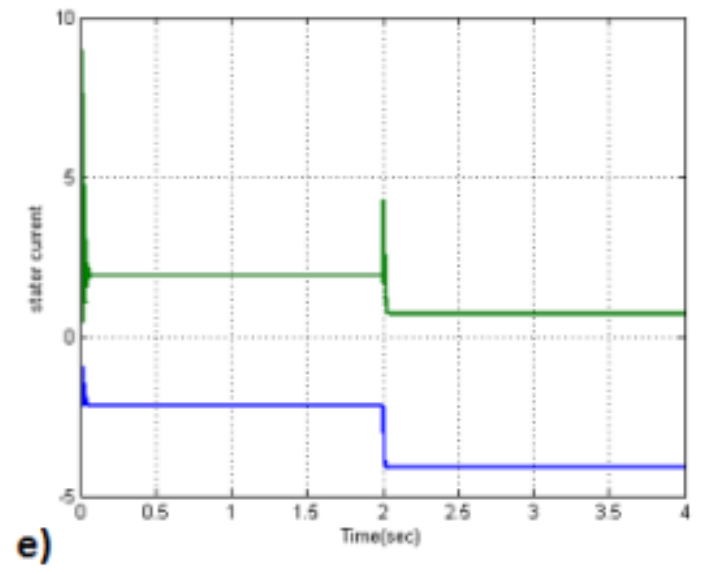

Figure 7: (a) Desired torque and output torque of system, (b) rotor flux, (c) active power, (d) reactive power, (e) stator flows. 
Table 3: The variables of the machine and required parameters for controlling methods.

\begin{tabular}{|c|c|c|}
\hline $\begin{array}{c}\text { Magnitude/ } \\
\text { Parameter }\end{array}$ & VC & DTC \\
\hline Vabc_r & - & - \\
\hline Vabc_s & $\checkmark$ & $\checkmark$ \\
\hline iab__r & $\checkmark$ & $\checkmark$ \\
\hline iab__s & $\checkmark$ & $\checkmark$ \\
\hline$\omega_{\mathrm{r}}$ & $\checkmark$ & - \\
\hline$\theta_{\mathrm{r}}$ & $\checkmark$ & $\checkmark$ \\
\hline LM & $\checkmark$ & $\checkmark$ \\
\hline Llr & $\checkmark$ & $\checkmark$ \\
\hline Lls & $\checkmark$ & - \\
\hline
\end{tabular}

Due to the use of frame variations, reference and the structure based on solving it, VC is one of the most complex controlling strategies. In Table 4 (Tremblay et al, 2011), transient response time for various controlling strategies has been presented while using various references.

Table 4: Transient response time for various controlling methods.

\begin{tabular}{|l|l|l|}
\hline \multirow{2}{*}{ Reference } & \multicolumn{2}{|l|}{$\begin{array}{l}\text { Transitory } \\
\text { Response }[\mathrm{ms}]\end{array}$} \\
\cline { 2 - 3 } & $\mathrm{VC}$ & $\mathrm{DTC}$ \\
\hline $\begin{array}{l}\text { Negative Reference Step: } \\
\mathrm{i}_{\mathrm{qr}}^{*} / \mathrm{T}_{\mathrm{e}}^{*} / \mathrm{P}_{\mathrm{s}}^{*}\end{array}$ & 10 & 2.5 \\
\hline $\begin{array}{l}\text { Positive Reference Step: } \\
\mathrm{i}_{\mathrm{qr}}^{*} / \mathrm{T}_{\mathrm{e}}^{*} / \mathrm{P}_{\mathrm{s}}^{*}\end{array}$ & 10 & 1.5 \\
\hline $\begin{array}{l}\text { Negative Reference Step: } \\
\mathrm{i}_{\mathrm{dr}}^{*} / \lambda_{\mathrm{r}}^{*} / \mathrm{Q}_{\mathrm{s}}^{*}\end{array}$ & 10 & 2.5 \\
\hline $\begin{array}{l}\text { Positive Reference Step: } \\
\mathrm{i}_{\mathrm{dr}}^{*} / \lambda_{\mathrm{r}}^{*} / \mathrm{Q}_{\mathrm{s}}^{*}\end{array}$ & 5 & 2.5 \\
\hline
\end{tabular}

Table 5 (Tremblay et al, 2011) is a summary of various presented results in this paper. Moreover, the following points are extracted from the results:

1. The complexity of calculations: in VC method, various reference transformations and its nature that is based on model made it a resource-consuming strategy. On the other hand, direct technique makes use of simpler data that mainly relies on hysterias comparator and tables; however, DTC method still requires precise estimation of rotor flux and measurement of six physical values.
2. The dependency on model: VC strategy is dependent on device parameters much more than DTC method.

3. Transient response: although dynamic response of VC is faster and better, direct control method presents better results.

Table 5: The comparison of quality performance.

\begin{tabular}{|l|l|l|}
\hline Performance Criterion & VC & DTC \\
\hline $\begin{array}{l}\text { Computational } \\
\text { complexity }\end{array}$ & High & High \\
\hline $\begin{array}{l}\text { Machine model } \\
\text { dependency }\end{array}$ & High & High \\
\hline Sample time constraints & Low & High \\
\hline Transitory response & Medium & Medium \\
\hline Settling time & Medium & Low \\
\hline Harmonic contents & Low & Medium \\
\hline $\begin{array}{l}\text { Instrumentation } \\
\text { constraints (sensor-wise) }\end{array}$ & Medium & High \\
\hline $\begin{array}{l}\text { Overall implementation } \\
\text { complexity }\end{array}$ & High & High \\
\hline Robustness & High & Medium \\
\hline MPPT suitability & High & High \\
\hline
\end{tabular}

\section{Conclusion}

As seen, VC is a very complex method due to the use of rotating reference frame and modelbased structure. In DTC method, this complexity has decreased with reduction of device parameters. Moreover, negative response of reference in transient response for VC method is 10; this value has decreased four times for DTC control method and reached 2.5. These results indicate improvement of transient response speed in DTC method. At the end, the comparison of the obtained results shows relative priority of DTC method.

\section{References}

Blaschke, F. (1974). Method for Controlling Asynchronous Machines. U.S. Patent 3824 437.

Chandrakala, B., Lakshmi Madhuri, Ch., Penchala Babu, V., Anil Kumar, K. (2012). Direct torque control for doubly-fed induction machine based wind turbines. International Journal of Engineering Science 
\& Advanced Technology [IJESAT], Volume-2, Issue-4, pp. 1035 - 1042.

Krause, P., Wasynczuk, O., Sudhoff, S. D. (2002). Analysis of Electric Machinery and Drive Systems. Hoboken, NJ: Wiley.

Nunes, M., Lopes, J., Zurn, H. (2004). Influence of the variable-speed wind generators in transient stability margin of the conventional generators integrated in electrical grids. IEEE Trans. Energy Conversion, vol. 19, no. 4, pp. 692-701.

Pena, R., Clare, J. C. (1996). Doubly fed induction generator using back to back PWM converters and its application to variable-speed wind energy generation. Proc. IEEE, Electric Power Applications, vol. 143, no. 3, pp. 231-241.

Shen, B., Mwinyiwiwa, B., Zhang, Y., Oo, B. T. (2009). Sensorless maximum power point tracking of wind by DFIG using rotor position phase lock loop (PLL). IEEE Trans. Power Electron., vol. 24, no. 4, pp. 942-951.

Tremblay, E., Atayde, S., Chandra, A. (2011). Comparative Study of Control Strategies for the Doubly Fed Induction Generator in Wind Energy Conversion Systems: A DSP-Based Implementation Approach. IEEE Trans. Sustainable Energy, vol. 2, no. 3, pp. 288-299.

Tremblay, E., Chandra, A., Lagace, P. (2006). Grid-side converter control of DFIG wind turbines to enhance power quality of distribution network. in Proc. 2006 IEEE Power Engineering Society General Meeting (PES 2006), Montreal, QC, Canada.

Tamalouzt, S., Rekioua, T., Abdessemed, R. (2014). Direct torque and reactive power control of Grid Connected Doubly Fed Induction Generator for the wind energy conversion. Electrical Sciences and Technologies in Maghreb (CISTEM), 2014 International Conference on, pp.1-7, Tunis, Maghreb.

World Wind Energy Association (WWEA) Report 2009 [Online] (2011). http://www.wwindea.org/home/index.php.

Xiang, D., Ran, L., Tavner, P. J., Yang, S. (2006). Control of a doubly fed induction generator in a wind turbine during grid fault ride- through. IEEE Trans. Energy Conversion, vol. 21, no. 3, pp. 652-662. 